accurate information we have so far deemed it unwise to try a second injection where the first was incompletely successful. Experimental work on the absorption of oil would be helpful.

6. Proctocaine was employed because it was the only preparation readily obtainable on the market for prolonged anaesthesia. The proportions of the ingredients were originally planned for effective rectal and anal anaesthesia only. Modifications of the constituents might quite probably give a better solution for orbital use. Further research would seem indicated.

7. If proctocaine is employed for the relief of pain in a blind eye, all possibility of neoplasm should be excluded (see Case $(n)$ ).

Proctocaine retrobulbar injections can be safely recommended for painful eyes with full corneal sensibility and poor vision. If vision is good in a painful eye, the possibility of producing temporary diplopia by the injection must be remembered. Neuroparalytic keratitis is a theoretical possibility if corneal sensitivity is unduly lowered, but so far this complication has not been met with in practice.

We wish to thank Messrs. A. D. Griffith, G. C. Pritchard, A. C. Reid, and H. M. Symons for their kindly advice and collaboration.

\title{
REFERENCES
}

Morgan, C. Naunton (1935).-Brit. Med.Jl., Vol. II, pp. 938-942.

SaInT-Martin, R. DE (1939).-Traité d'ophtal., Vol. VII, p. 423.

\section{CONVERGENCE WEAKNESS}

BY

\section{O. GAYER MORgaN}

LONDON

I HAVE been interested in these cases of defective convergence for some time, and one of the things that surprised me was that quite a number of people seemed to have no convergence at all, and yet had no symptoms of eye strain with near work or reading.

Stutterheim's monograph was extremely interesting and made me look out more for the cases with defective convergence and symptoms, but I felt that he laid too much stress on the muscles and too little stress on the brain. His method of training tended to underestimate the value of explanation.

The whole condition is very important because of the number of people who show the condition and the severity of the clinical symptoms which can arise from it. 
I should like to take one case in some detail because it illustrates an average degree of disability and is not in any way unusual.

A young man aged 22, who when I first saw him was wearing Rt. Eye -3.0 D.cyl. $k$, Lt. Eye -2.0 D.cyl $\downarrow$, and had 6/6 vision $60^{\circ}$ $110^{\circ}$

in each eye. He had worn glasses since the age of eight.

The glasses were changed fairly frequently, sometimes at hospital, sometimes by the optician, but he always had difficulty in doing continuous work, and at one time was removed from school for a term and sent to the country. He was usually better for a time after a change in his glasses. At 18 he left school and started clerical work and also night classes. When aged 19 he had a great deal of trouble, headaches, failure of concentration and photophobia. At times there was a pain at the back of his eyes producing a feeling of nausea.

Crookes' lenses were prescribed with some relief, but he then went in for an examination and the difficulty in concentration and the tense feeling in his eyes began to upset him so much that he could not sleep. He became very nervy and would not buy a paper or read a book. He began to feel that his future was in jeopardy and although he was physically fit and took plenty of exercise his general condition began to deteriorate. A holiday usually gave temporary improvement.

At this stage prisms were prescribed by an optician, but with no improvement. When I saw him at the the age of 22 he was in an extremely pessimistic mood, and thought of giving up clerical work altogether.

On examining his muscle balance he was orthophoric with the Maddox rod for distance with $5^{\circ}$ amplitude of convergence. Fusion was poor and there was definite suppression present. He could do none of the positions on the diploscope. I sent him to the Orthoptic Department. After six treatments he had $30^{\circ}$ amplitude of convergence and he found quite suddenly that he could manage some of the positions on the diploscope. After nine treatments his amplitude was $40^{\circ}$ and he could use the diploscope in all positions. $\mathrm{He}$ said he felt much better, could travel comfortably in a train and look out of the window, objects were clearer and more defined, and did not appear to tumble towards him as they had done at times before.

At this point in the treatment he developed $3^{\circ}$ of right hyperphoria when the eyes were converged to his full $40^{\circ}$, but there was none when he looked straight ahead.

He was discharged after 16 treatments. There was a slight relapse three months later after a particularly hard bout of work, but two more treatments set this right and there has been no relapse since then. 
Another patient, a clerk, aged 40 years, amongst other symptoms of eye strain. had extreme mental depression for which he was under treatment by a psychologist. He had no error of refraction but had received all types of glasses in his time, including bifocals with full correction for near. $\mathrm{He}$ was exophoric $2^{\Delta}$ for distance and had no notion of convergence at all. On attempting to converge he broke out into a profuse perspiration and became excessively fatigued. In ten treatments he had obtained $20^{\circ}$ of convergence and although this never seemed to improve very much it was sufficient to banish nearly all his symptoms.

My next case illustrates the mental factor in another way. The patient, a female, aged 47 years, wearing about $-4 \cdot 0 \mathrm{D}$. in each eye could not sew or read for long, and was getting headaches. She was exophoric $5^{\Delta}$ for distance and about $20=$ for near on the wing test. On asking her to converge on my finger she made such an effort that her eyes seemed to diverge slightly though she had no diplopia. On getting her to read I found that her eyes did converge slightly and she could bar read, and it was only when the book was brought quite close, if this was done slowly whilst she was reading, that divergence and suppression suddenly appeared. With treatment she improved considerably and could eventually converge on the finger and do the positions on the diploscope.

There is no doubt that the condition does occur in children but in the majority of cases there are few if any symptoms.

It is certainly a central failure because the training in some cases is quite rapid, depending on how quickly the patient understands what is required of him. He does not seem to know what convergence is, though the nerve paths and the muscular ability are present all the time. It seems to be a subconscious suppression of an associated movement.

The treatment of these cases hardly ever seems to fail, and the average number of attendances in my cases has been sixteen. The first thing to do, as Miss Mann has shewn, is to explain in simple language what is wrong, then to make them understand physiological diplopia, then to overcome the almost constant suppression which is found, and then to improve convergence power on the synoptophore and to use the diploscope which can be taken home when the patient can manage all the movements and positions. 